\title{
Operating Experience of Country's Agricultural Science and Technological Park
}

\author{
Hui Yang1, Xiuling Li², Jian Kang3 \\ ${ }^{1}$ Editorial Department of Journal, The Academic Theory Research, Heilongjiang Bayi Agricultural University, Daqing, China \\ ${ }^{2}$ Technological Bureau of Heilongjiang, Zhaozhou, China \\ ${ }^{3}$ Ministry Bureau of Heilongjiang, Suibin, China \\ Email: 16299544@qq.com
}

How to cite this paper: Yang, H., Li, X.L. and Kang, J. (2018) Operating Experience of Country's Agricultural Science and Technological Park. Agricultural Sciences, 9, 228-235.

https://doi.org/10.4236/as.2018.92017

Received: January 15, 2018

Accepted: February 25, 2018

Published: February 28, 2018

Copyright $\odot 2018$ by authors and Scientific Research Publishing Inc.

This work is licensed under the Creative

Commons Attribution International

License (CC BY 4.0).

http://creativecommons.org/licenses/by/4.0/

\begin{abstract}
Through the analysis of the operation of China's agricultural science technological and development process, the paper summed up the basic experience of agricultural science technological park and operation mode, in order to run at all levels of agricultural science technological park of science and regional some beneficial references for the development of agricultural economy.
\end{abstract}

\section{Keywords}

Agricultural Science and Technological Park, Experience, Pattern

\section{Introduction}

Agricultural science and technological park takes "science and technological rise park, industry strong park, ecological erect park" as the center, adheres to the government leading, enterprise main body, market orientation and the benefit drive, develops efficient ecological agriculture as the main body with efficient and intensive utilization of resources, relies on a "1" local resources and " $\mathrm{N}$ " elements demonstration zone of agricultural science and technological park in accordance with the " $1+\mathrm{N}$ " overall architecture planning in order to pull the development of regional agricultural economy, strengthen the construction of ecological environment and infrastructure, promote the coordinated development of the fusion of "one-two-three" industry. The paper summed up the following experience through summarizing the part operation of the nationwide agricultural science and technological park [1] [2]. 


\section{Organizing Park, Building "Funnel"}

From the point of regional development, agricultural and sideline products processing zone is the "funnel" of regional economic development, the "funnel" can fully integrate the resources collection, gather talents, absorb technological and enterprises, spin industry chain, improve the added value of agricultural and sideline products, increase agricultural market adaptability and ability to resist risks, it is also a "funnel effect" in the development of regional economy. At present, the most cores of the national agriculture science and technological park have become the development of regional agricultural industry leader.

\section{Multi-Cooperation, Coordinated Development}

\subsection{Government Pushing}

All levels of government research decide scientifically to issue and implement a series of policies and promote the efficient development of agricultural industry according to the actual local agricultural environment and resources condition. In the process of planning for the development of agricultural industry, all levels of government should focus on combing the industrial structure, analyzing the development direction, clearing leading industry, optimizing the industrial layout, building the regional advantages of " $1+\mathrm{N}$ " the agricultural industry development pattern, which laid a good industrial basis for the scientific development of regional economy.

\subsection{Enterprise-Leading Affects}

To support and cultivate a batch of the backbone of the leading enterprises with the high technological content, large market share, strong radiation, it is applied to expand agricultural production function, extend the industrial chain and promote the healthy development of the agricultural industry.

The development of agricultural industry just like on the train, as power car is agricultural products processing enterprises; the car is the production base; track and roadbed is policy and social environment; driving direction is the demand of the market; car and car link is the operating mechanism of industrialization of industry. The train runs fast to provide a strong power for regional agricultural industry development [3] [4].

\subsection{Market Pulling}

Agricultural science and technological park according to their own conditions and resource endowment, it guided by market demand, comply with the laws of market development, and further optimize the structure of agricultural industry, focus on development on market competitiveness of the agricultural production projects, enhance the market adaptability and competitiveness of agriculture, boost the depth of the agricultural industry development. The agricultural industry gradually becomes the bigger and stronger. 


\subsection{Science and Technological Propelling}

All various levels park must integrate science and technological resources, scientific and technological personnel, build science and technological service platform, further improve the ability of agricultural science and technological innovation, speed up the transformation of scientific and technological achievements, popularize the use of advanced technological, constantly improve the contribution rate of science and technological.

Agricultural science and technological park should cooperate with many universities and research institutes to carry out scientific research, construct university-industry cooperation incubation base of agricultural science and technological innovation and achievements transformation. The base could actively promote the park enterprises to carry out the innovation of science and technological research, carry out the technological innovation and product upgrade, and help production base for introducing the advanced technological and developing the technical personnel training, etc., actively explore a variety of effective way of scientific research cooperation to facilitate the transformation of scientific and technological achievements [5].

Historical experience has shown that technological science can strong the enterprise, prosper the technological industry and be rich the agriculture, which is an important experience of the agricultural industry rapid development of strong economic development.

\subsection{Many Aspects Interacting}

All regions should be based on local resources and natural conditions, determine the key development area advantage of agricultural industrial chain, clear about the focus on the development of agricultural industry and development direction, and adjust measures to local conditions to the production base of scientific planning and rational layout to optimize the allocation of resources, intensive coordination management and the organization's set of standard production. In the process of agricultural development, the government-industry-university-research cooperation can seek common ground, build consensus and coordinate each other [6] [7]. The parties to the contract would take the interest as the link and the contract as constrain, and all parties are going to be concentric, synthetic, fellow, mutual cooperation, mutual benefit for promoting the agricultural science and technological park, the regional agriculture development and the new rural construction.

\subsection{Farmers Acting}

Farmers are the main body of agricultural development and new rural construction, and they are not only direct undertaker, but also direct beneficiaries. In the process of regional agriculture development and new rural construction, the government fully respects the wishes of farmers, and introduces the policy support to guide farmers to form a production cooperatives, and actively take part 
in the agricultural science and technological park and the new rural construction. At the same time, the government takes many effective measures to ensure agricultural efficiency and farmers' income, guarantee the smooth development of regional agriculture and new rural construction [8].

\section{Accelerate Convergence, Integrated Propulsion}

Agricultural industry is a complicated system engineering, not only requires the internal structure optimization, but also be suitable for the external. In the process of agricultural development, we should comprehensively considerate the national, provincial and municipal agricultural development environment, make full use of the favorable opportunity for development, promote the economic development of regional economy and national, provincial and municipal depth fusion, and propel regional integration of the agricultural economic development.

\subsection{Promoting Fusion of "One, Two, Three" Industry}

The coordinated development of agriculture, industry and service industry is considered comprehensively at the same time of strengthening crops and livestock and poultry breeding, whole would propel leisure tourism, agricultural education, specialty food, green livestock products, the rapid development of the logistics, it can make the depth fusion of "one-two-three" industry, further extend agriculture industry chain, promote the development of the depth of the agricultural industrialization.

\subsection{Promoting and "Belt and Road" Fusion}

Giving full play to the efficiency of agricultural science and technological park advantage, the area regional economic development will be fully integrated into the national development strategy of "Belt and Road". The agricultural science and technological park is attempted to make the important base node or development of "Belt and Road" in order to make full use of the favorable development opportunity to promote regional economic development.

\subsection{Promoting and Fusion of Web of Things}

Agricultural science and technological park should accelerate the construction of cold chain logistics of livestock products, build trading platform of livestock products, promote the rapid development of the regional internet of things. Pulling of the internet things can promote regional agricultural production to presents the good development momentum, and make "production-process-sell" system to run smooth.

\subsection{Fusion of Industry and City}

In the process of the construction of agricultural development at all levels, we 
actively expand demonstration area and radiation zone, adopt the various effective measures, and the park will be constructed the new pattern of social development including "industry-city" integration, "town-garden" integration, "urban-rural" integration to comprehensively promote the "workers-peasants" integration.

\section{Optimization Model, Innovating Mechanism}

In the process of the development of agricultural industry, we should carry out discussions of multi-level, many regional agricultural industrial development mode and operation mechanism, especially in the process of operation of agricultural science and technological park, we must continuous reform and innovate, gradually form and optimize the industrial development pattern and innovation mechanism, which promote the deep development of agricultural science and technological park.

\subsection{Optimizing the Mode of Agricultural Development}

Agricultural development pattern includes the industrialization mode, cooperative mode, science and technological innovation mode and new countryside building mode. Industry models can be divided into basic pattern and optimized pattern. Basic mode is as follow [9] [10]: "leading enterprises + production base + cooperative + producers" industrialized development mode. Optimized pattern is as follow: enterprise group establish the industrialized development mode, and enterprise group unify planning.

Multi-cooperation pattern: through the government leading, the pattern can receive multi-strength and coordinate development. Main features are as follows: waving administrative hand, pulling the market hand, driving leading enterprises, promoting science and technological innovation, acting cooperation organization, pushing urban rural interaction.

Science and technological innovation pattern: main features of this pattern are as follows: building of school and county, cooperation of college and enterprise, joint research, science and technological correspondent, outsourcing project.

New rural build mode: main feature of this pattern is the common construction of schools, urban and rural areas, enterprises and social cooperation.

\subsection{Innovating Mechanism of Agricultural Science and Technological Park}

The running of livestock products processing park adopts the combinated management system of the local agency and enterprise operation, it is a " $1+1+\mathrm{N}$ " pattern.

"1" as one party of the government management committee, the main responsibility is to coordinate, macroscopically manage and serve enterprises, and it would provide the service of the enterprise development.

" 1 " as one party of the fund management companies, the main responsibility 
is to manage the fund operation activities of fund raising, fund of share subscription and redemption, the fund property investment, income distribution, etc. Fund management companies adopt the multi-channel funds to support the development of park enterprises.

"N" as the introduced or setting up several industry funds, it will be in accordance with the relevant regulations and management measures to participate in the use of funds, supervise the behaviors of fund companies, maintain the reasonable application of fund channel and the interests of investors.

In the process of concrete operation, the used mechanisms are as follows:

1) System of running company: the agricultural science and technological park set up the modern investment management company of possessing the legal person qualification, operating independently, the company can carry out the development and implementation of project management and enterprise management.

2) System of investment owner: the construction of agricultural science and technological park strictly implements the investment of private running, and encourages the leading agricultural enterprise with the legal person qualification and the agricultural development company to invest. This system can give full play of market mechanism, benefit to the investors, clear property rights and form a "multi-channel" and diversified investment system.

3) Contract system of science and technological promotion: the system is to encourage the agricultural science and technological professionals, and the professionals may sign the technical contract with farmers and carry out the demonstration works of agricultural science and technological popularization.

4) System of connecting peasant household contract: the leading enterprises sign the production and sales contract in accordance with the requirements of the agricultural industrialization management to provide supported service, and the contract must clear benefit and responsibility of both sides, form a risk-sharing and sharing economic community.

5) System of talent introduction and employment: the park may face the whole country to overtly recruit the scientific and technological talents according to their own development needs. Its purpose is to fundamentally enhance the supported ability of the scientific and technological park development.

\section{Highlighting Characteristics, Circulating Green}

The regional agriculture industry as the core of agricultural science and technological park should be based on their own advantages and industry characteristics, and four economic developments are focused on the following:

1) Developing the leading economy. Based on the processing zone, it increase the number of leading enterprises, improve the traction of leading enterprises, promote the integration of leading enterprises, form the regional characteristics of leading enterprises

2) Developing the circle economy. The platform of processing industrial park 
may absorb, drive and affect the regional resources of enterprise and talent, and make the agricultural cooperative development of different region, complementary resources circle and business circle.

3) Developing the shadow economy. The shadow economy is to play a demonstration of the agricultural science and technological park of core-processing, leading role, and it will form a complete set of technical system of applying the advanced management experience and scientific operation mechanism, optimizing development pattern to promote the healthy development of regional agriculture industry.

4) Developing the green economy. The green economy can make full use of the high quality of agricultural resources and ecological environment conditions. Based on the traceability system, it may implement the standard of green food production technology in crop planting, livestock farming, deep processing of livestock products and marketing, and may product the green food to make green economy as the strategic brand of the regional agriculture development.

\section{Conclusion}

Through the construction and operation of agricultural science and technological park, the conclusions are as follows: agricultural science and technological park is the huge driving force and leading of agriculture development, and the supporting of science and technology is a key to develop the agricultural science and technological park; the development of agriculture industry is to promote the development of agricultural industrialization and regional economic development; the construction of agricultural science and technological park and fusion of "one-two-three" industry are the effective means of promoting structural reform of agricultural industrial structure adjustment

\section{Funding}

The work is supported by philosophy and social sciences planning research project of Daqing city (DSGB2016081).

\section{References}

[1] Wang, Z.P., Li, J.E., Feng, Y., et al. (2015) The Thinking of Construction of Agricultural Science and Technology Demonstration Garden about Funing County. Yunnan Science and Technology Management, 5, 39-40.

[2] Fu, C.N., Zhang, S.J., Liang, X.Y., et al. (2016) The Present Situation and Development Countermeasures of Industrialization of Sweet Sorghum Research in Gansu Province. Sugar Crops of China, 38, 76-78.

[3] Long, T.W. and Su, J.J. (2007) Improving the Capacity of National Agricultural Science and Technology Park of Sustainable Development Strategy and Countermeasure. Scientific and Technological Progress and Countermeasures, 24, 24-25.

[4] Chen, L.H. (2012) Ignoring the Production Safety of Combine Harvester. Agricultural Equipment and Technology, 38, 36-37. 
[5] Zhang, S.B. (2009) System Research of Modern Multi-Functional Agriculture Evaluation. Doctoral Dissertation of Hunan Agricultural University, Changsha.

[6] Huang, Z.J. and Zhang, Q.H. (2014) Science and Technology Park of Collaborative Innovation Research. Scientific Management Research, 32, 25-27.

[7] Liu, Z.C. and Chen, X.D. (2015) The Research on the Correlation between the Innovation Ecosystem and the Innovation Efficiency of Science and Technology Park. Science Research Management, 32, 26-31.

[8] Zhu, Y.J. and Sun, Z. (2016) Empirical Studies on Innovations in Systems and Mechanisms of Sci-Tech Parks at Home and Abroad. Jiangsu Science \& Technology Information, 31, 1-3.

[9] Lu, W.J. (2016) Science and Technology Park Construction Operations. Business Review, 36, 7-8.

[10] Chen, S.X., Lei, H.H. and Cha, J.Q. (2002) Research of Operation Mechanism of Agricultural Science and Technology Park. Science and Technology Management, 1, 93-94. 